\title{
A Structural Analysis Between Mindset, Grit, and Self-Directed Learning Ability of Children according to Attachment Type
}

\author{
Min-Kyu Cho \\ Department of Child Studies, Kyungpook National University, Daegu, Korea \\ 애착유형에 따른 아동의 마인드셋, 그릿, 자기주도 학습능력 간 구조분석 \\ 조민규 \\ 경북대학교 아동학부
}

Objectives: The relationship between mindset, grit, and self-directed learning ability of children is examined by attachment type.

Methods: A survey was conducted on 815 elementary school students in grades 5-6 belonging to the Gyeonsangbuk-do office of education. The analysis method used latent mean and multi-group analyses.

Results: Results revealed significant differences between mindset, grit, and self-directed learning ability according to childhood attachment type. Further, there was a significant difference in the path from growth mindset to grit and intrinsic motivation according to childhood attachment type.

Conclusion: Through research was found that childhood attachment is an important factor in improving children's mindset, grit, and self-directed learning ability.

Keywords: mindset, grit, self-directed learning ability, attachment type

\section{Introduction}

자기주도 학습능력은 학습자가 학습의 과정을 주도하여 자신 에게 가장 적절한 지식을 구성, 기술을 습득하는 능력을 의미 하는 것으로(Y. H. Park, 2003), 이러한 과정을 통해서 아동들 은 내재적으로 동기화가 되며, 사고의 전환이 이루어지며, 실 제 행동에 있어서도 적극성을 발휘하게 되는 것이다. 이를 세 가지 범주로 구성하면 인지중심, 동기중심, 행동중심이라는 용어로 구성될 수 있다(Yang, 2002). 인지중심은 메타인지라 는 용어로 설명될 수 있는데, 학습자가 학습을 행하는데 있어 서 자신만의 전략을 통해 학습자료를 의미 있는 방식으로 이 해하는 능력을 말한다(Zimmerman, 2008). 즉, 아동이 자신에

Corresponding Author: Min-Kyu Cho, Department of Child Studies, Kyungpook National University, 80, Daehak-ro, Buk-gu, Daegu, Korea E-mail: familystark@naver.com
게 맞는 효과적 인지전략을 선택하고 통제하는 능력은 자기주 도 학습능력을 높이는 중요한 요소로 작용하는 것이다(Corno \& Mandinach, 1983). 동기중심은 내재적 동기 혹은 성취감, 자 아효능감이라는 용어로 설명될 수 있는데, 학습자가 자신만 의 학습전략을 실행하기 위한 동기부여의 중요성을 말한다 (Pintrich, Marx, \& Boyle, 1993). 행동중심은 정보탐색 혹은 과 제해결 능력으로 설명될 수 있는데, 학습자가 학습을 최적화 하기 위한 사회적, 물리적인 환경을 스스로 선택하여 구조화 및 정보를 탐색하는 실제적으로 행동을 실천하는 능력을 말 한다(Y. H. Park, 2003). 자신의 목표를 선정하기 까지 과정에 서 동기중심의 자기주도 학습능력은 매우 중요한 요소를 작용 하지만, 목표를 정한 후 그 과제에 대해 실행하여 해결, 정보를

(C)The Korean Association of Child Studies

This is an Open Access article distributed under the terms of the Creative Commons Attribution Non-Commercial License (http:// creativecommons.org/licenses/by-nc/4.0) which permits unrestricted noncommercial use, distribution, and reproduction in any medium, provided the original work is properly cited. 
탐색하는 능력 또한 중요하므로 행동중심의 자기주도 학습능 력 또한 매우 중요한 요소이다(Fernald \& Kuhl, 1987). 이처럼, 자기주도 학습능력은 한 가지 차원으로 설명되는 것이 아닌 아동의 학습능력을 높이기 위해 다양한 차원에서의 접근이 필 요하다는 점을 알 수 있다. 따라서 본 연구에서는 자기주도 학 습능력의 세 가지 차원(인지, 동기, 행동)의 원인변수를 탐색 해 보고자 한다.

아동의 자기주도 학습능력을 키우기 위한 방안으로 그들 이 가진 마인드셋을 파악해볼 필요가 있다(Claro, Paunesku, \& Dweck, 2016). 마인드셋은 자신의 지능·능력에 대한 신념을 의 미하는 것으로, 자신의 능력이 긍정적으로 변화할 수 있다고 생각하는 성장마인드셋과 아무리 노력 하더라도 자신의 지능 이나 능력은 변화될 수 없다고 여기는 고정마인드셋으로 구 분될 수 있다(Dweck, 2007). 변화를 가져올 수 없다고 생각하 는 고정마인드셋이 높은 사람은 환경적 어려움에 직면하였을 때 이를 극복하는 힘이 부족한 반면, 자신의 변화가능성을 믿 는 성장마인드셋이 높은 사람은 환경적 어려움에 직면하였을 때 더 잘 견뎌낼 수 있게 된다(Fitzgerald \& Laurian-Fitzgerald, 2016).

동일한 지적 능력을 가진 아동들이라도 자신의 지능에 대 한 신념을 어떻게 가지는가에 따라서 그들의 학습을 행하 는 태도가 달라질 수 있다(Blackwell, Trzesniewski, \& Dweck, 2007). 역경을 마주 하였을 때 고정마인드셋을 가진 학생들보 다 성장마인드셋을 가진 학생은 더 높은 학습목표지향의 특 성을 보인다(Dweck \& Leggett, 1988). 학습과정 중 문제가 발 생하였을 때 성장마인드셋이 높은 학생들은 문제해결 과정에 서 어려움을 겪더라도 과제를 해결할 수 있다는 신념을 가지 게 되고, 이를 해결하려는 행동 중심의 학습능력이 높아지게 되는 것이다(Dweck, Chiu, \& Hong, 1995). 성장마인드셋이 높 을 경우 자신이 처한 상황에서 성공 혹은 실패에 대해 얼마나 더 발전해야 하는가를 판단하는 인지전략이 높아질 수 있다 는 점에서(Molden \& Dweck, 2006), 성장마인드셋은 아동들의 과제에 대한 고차원적 학습능력을 가지게 한다고 할 수 있다 (Dweck, 2007).

자기주도 학습능력을 예측하기 위한 또 다른 원인변수로 그릿은 매우 중요한 역할을 하고 있다(Duckworth \& Quinn, 2009). 그릿은 장기적 목표를 이루기 위한 인내심과 끈기, 열 정을 의미하는 것으로, 장기적 목표를 달성하는 과정에서 겪 게 되는 실패와 역경을 겪었을 때 도전하고 노력하여 관심을 유지시키는 원천이 된다(Duckworth, Peterson, Matthews, \& Kelly, 2007). 그릿과 자기주도 학습능력 간 관련성을 살펴보
면, 자기주도 학습능력 요인들 중 목표를 추구하는 과정과 관 련성을 가지며, 스스로 자신의 행동을 통제하고 조절하는 행 동적 차원과도 관련성이 깊다(Duckworth, Quinn, \& Seligman, 2009). 그릿의 주요개념인 노력의 꾸준함 요인은 목표달성을 위해 끝까지 정진하는 것을 의미하는데, 이러한 꾸준함을 가 질 경우 자기주도 학습능력 중 동기부여를 위한 성취감을 향 상시키는 원인변수로 작용할 수 있다는 측면(Duckworth \& Gross, 2014)은 자기주도 학습능력의 원인변수로써 그릿에 대 한 연구가 매우 필요하다.

자기주도 학습능력의 원인변수인 그릿은 마인드셋의 결과 변수로 작용할 수 있다(Myers, Wang, Black, Bugescu, \& Hoeft, 2016). West 등(2016)은 마인드셋과 그릿 요인 간 매우 밀접한 관련성을 보고하고 있으며, 성장마인드셋이 높은 학생들은 높 은 그릿을 보인다는 측면(Eskreis-Winkler, Gross, \& Duckworth, 2016)은 그릿의 원인변수로 마인드셋이 중요한 역할을 하고 있음을 말해주고 있다. 성장마인드셋 성향이 높을수록 목표를 추구하는 과정에서의 변화의 가능성을 긍정적으로 인식하기 때문에 장기적 관점의 목표에 대한 끈기와 열정을 높여주는 것이다(S. Lee, 2016).

본격적인 사회적 상호작용을 시작하는 아동기는 주 양육자 와의 긍정적 관계가 무엇보다 중요하다. 태어나는 순간 부모 와의 접촉에서 시작되는 애착은 아동의 정서와 표현에 있어 서 도움을 주는 결정적 역할을 하는 매우 중요한 요소이다(J. $\mathrm{Kim}, 2012)$. 어머니와의 안정적 애착관계를 형성한 아동은 환 경에 대한 통제력을 제공하여 행동에서의 대응양식을 형성하 게 되며, 자신의 행동과 감정을 이해하고 상황에 따라 적절하 게 행동하고 통제하는 능력이 향상되게 된다(J. Y. Lee \& Baek, 2009). 또한, 안정애착은 아동의 자아존중감 및 효능감 향상에 주요요인으로 작용할 수 있다는 측면(You \& Lee, 2005)에 자기 주도 학습능력을 파악하기 전 그들의 애착유형에 대한 차이검 증이 선행될 필요가 있다.

애착과 마인드셋 관련 선행연구를 살펴보면 안정애착을 가 진 사람들은 변화가능성 또한 높을 수 있으며(Skogland, 2017), 마인드셋을 형성하는데 있어서 애착패턴은 원인변수로 작용 할 수 있다고 보고한 Galen (2011)의 연구는 애착유형에 따른 마인드셋의 차이를 살펴볼 필요성을 말하고 있다.

애착과 그릿 간 관련성을 연구한 Levy와 Steele (2011)은 안 정애착을 가진 사람들은 낮은 불안과 회피를 보이기 때문에 그릿이 높아질 수 있지만, 회피 혹은 불안수준이 높은 불안정 애착을 지닌 사람들은 그릿이 낮아질 수 있다고 보고하고 있 다. 또한, 높은 그릿 점수를 보이는 사람들은 안정애착 경험을 
동반하고 있다고 보고한 연구결과(Coppola, Vaughn, Cassiba, $\&$ Costantini, 2006)는 그릿을 파악하기 위한 선행연구로 애착 유형에 따른 차이를 검증할 필요가 있음을 보고하고 있다.

기존의 연구에서는 마인드셋 전체 값을 중심으로 연구가 진행되고 있는데, 고정마인드셋의 경우 부정적 의미를 내포하 기 때문에 역문항 처리하여 마인드셋 전체값을 중심으로 한 연구가 진행되고 있으며, 고정마인드셋을 제외한 긍정적 의 미의 성장마인드셋을 중심으로 연구가 진행되어 왔다(Jeon, 2018; Kwon, 2018). 하지만 본 연구에서는 각각의 마인드셋이 미치는 영향을 검증함으로써, 마인드셋의 부정 혹은 긍정적 영향력을 살펴보고자 하기 때문에 매우 필요하다. 둘째, 자기 주도 학습능력 관련 선행연구들을 살펴보면 주로 학습능력을 가진 학습자들의 학습과정에 전반에 대한 연구들이 이루어졌 으나, 본 연구에서는 아동의 자기주도학습 능력을 높이기 위 한 구체적 방안을 발견하기 위해 인지적 차원의 메타인지, 동 기적 차원의 내재적 동기, 행동적 차원의 과제해결 능력 각각 의 변수에 대한 원인변수를 탐색하고자 한다는 측면에서 매 우 필요하다. 끝으로, 본 연구에서는 마인드셋 관련 인과관계 검증을 비롯한 아동기 가장 중요한 요인 중 하나인 애착유형 별 차이, 이를 토대로 한 인과관계에서의 영향력 차이를 검증 해봄으로써 아동기 안정애착 형성의 중요성을 밝힐 수 있다는 측면에서 본 연구는 매우 필요하다. 연구문제는 다음과 같다.

\section{연구문제 1}

애착유형에 따른 아동의 마인드셋, 그릿, 자기주도 학습능력 의 차이는 어떠한가?

\section{연구문제 2}

아동의 마인드셋과 그릿, 자기주도 학습능력 간 인과관계에 서 애착유형에 따른 영향력의 차이는 어떠한가?

2-1. 아동의 마인드셋과 자기주도 학습능력 간 인과관계에 서 애착유형에 따른 영향력의 차이는 어떠한가?

2-2. 아동의 그릿과 자기주도 학습능력 간 인과관계에서 애 착유형에 따른 영향력의 차이는 어떠한가?

2-3. 아동의 마인드셋과 그릿 간 인과관계에서 애착유형에 따른 영향력의 차이는 어떠한가?

\section{Methods}

\section{연구대상}

본 연구에서는 경북교육청에 소속된 초등학생 5-6학년 815 명을 대상으로 온라인 설문조사를 실시하였다. 정보보호법 에 따른 개인정보 및 응답내용 이용에 대한 동의서를 배포하 였으며, 이용에 동의하지 않는 학생 10 명과 누락되거나 불성 실한 응답을 한 학생 8명을 제외한 최종 797명을 대상으로 연 구 분석을 실시하였다. 연구 대상자들의 인구사회학적 특성 은 Table 1과 같다. 성별에 따른 특성을 살펴보면, 남학생이 $52.4 \%$ 로 여학생(47.6\%)에 비해 높은 빈도를 보이고 있다. 다 음으로, 학년에 따른 특성을 살펴보면, 5학년이 403명(50.6\%) 으로 6학년(394명, 49.4\%)에 비해 높은 빈도를 보이고 있다. 끝으로, 출생순위 별 특성으로는 첫째 411 명(51.6\%), 둘째 (312명, 39.1\%), 셋째(60명, 7.5\%) 순으로 높은 빈도를 보이고 있다.

Table 1

Descriptive Characteristics of Participants

\begin{tabular}{|c|c|c|c|}
\hline \multicolumn{2}{|c|}{ Variables } & \multirow{2}{*}{$\frac{n}{418}$} & \multirow{2}{*}{$\frac{\%}{52.4}$} \\
\hline Gender & Boy & & \\
\hline & Girl & 379 & 47.6 \\
\hline \multirow[t]{2}{*}{ Age of class children } & 5 & 403 & 50.6 \\
\hline & 6 & 394 & 49.4 \\
\hline \multirow[t]{4}{*}{ Birth order } & First & 411 & 51.6 \\
\hline & Second & 312 & 39.1 \\
\hline & Third & 60 & 7.5 \\
\hline & Fourth or more & 14 & 1.8 \\
\hline Total & & 797 & 100 \\
\hline
\end{tabular}

\section{연구도구}

\section{아동기 애착유형}

아동의 애착유형을 평가하기 위해 Hazan과 Shaver (1987)가 개 발한 성인애착유형 척도를 Muris, Mayer와 Meesters (2000)가 아동용으로 수정.보완한 자료를 활용하였다. 본 척도에서 설 명하는 아동기 애착유형은 안정형, 회피형, 양가형(불안)으로 구성되어 있다. 유형분류를 위해 각 문항에 대한 점수를 부여 한 후 최종적으로 본인과 가장 일치하는 유형 한 가지를 선택 하여 아동들의 애착유형을 분류하게 된다. 


\section{마인드셋}

아동의 마인드셋을 평가하기 위하여 Dweck (2007)이 개발한 마인드셋 척도를 J. Park (2017)이 번안한 자료를 활용하였다. 본 척도의 하위요인은 성장마인드셋과 고정마인드셋 2 가지 하위요인으로 구성되어 있으며, 문항은 총 8 문항이다. 본 연구 에서는 성장 및 고정마인드셋 각각의 요인에 대한 인과관계를 검증하고자 하는 목적으로 문항꾸러미화를 통하여 성장마인 드 1 과 성장마인드 2 를 성장마인드셋의 지표변수로 선정하였 으며, 고정마인드 1 과 고정마인드 2 를 고정마인드셋의 지표 변수로 선정하였다. 연구에 사용된 문항은 총 8 문항이다. 척도 의 응답방식은 Likert식 5점 척도로 마인드셋 수준에 따라 전 혀 그렇지 않다(1점), 매우 그렇다(5점)로 구성되어 있으며, 하 위요인의 평균점수가 높을수록 자신의 능력이 긍정적으로 변 화될 수 있다(성장마인드셋) 혹은 변화될 수 없다(고정마인드 셋)는 신념이 높다는 것을 의미한다. 문항 간 내적합치도를 살 펴보기 위하여 신뢰도(Cronbach's $\alpha$ )를 분석한 결과, 성장마인 드셋 .93 , 고정마인드셋 .92로 나타났다.

\section{그릿}

아동의 그릿을 평가하기 위하여 Duckworth와 Quinn (2009)이 타당화한 Short Grit Scale (Grit-S) 척도를 H.-M. Kim과 Hwang (2015)이 초등학생용으로 번안 및 타당화한 자료를 활용하였 다. 본 척도의 하위요인은 노력의 지속성과 관심의 일관성 2 가 지 하위요인으로 구성되어 있으며, 문항은 총 8 문항이다. 척도 의 응답방식은 Likert식 5점 척도로 끈기의 수준에 따라 전혀 그렇지 않다(1점), 매우 그렇다(5점)로 구성되어 있으며, 관심 의 일관성 문항을 역문항 처리하여 평균점수가 높을수록 관심 의 일관성(열정)이 높다는 것을 의미한다. 문항 간 내적합치도 를 살펴보기 위하여 신뢰도를 분석한 결과 전체 .69로 나타났 으며, 하위요인별로 살펴보면 노력의 지속성 .71, 관심의 일관 성 .73으로 나타났다.

\section{자기주도 학습능력}

아동의 자기주도 학습능력을 평가하기 위하여 Y. H. Park (2003)가 개발한 척도를 $\operatorname{Han}$ (2010)이 수정.보완한 자료를 활 용하였다. 본 척도의 하위요인은 주인의식(효능감), 메타인지, 정보탐색 및 과제해결, 내재적 동기 및 자기성찰로 구성되어 있다. 주인의식(효능감)의 경우 동기적 영역에 포함될 수 있다
는 Zimmerman (1989)의 연구결과를 토대로 인지차원의 메타 인지, 행동차원의 정보탐색 및 과제해결, 동기차원의 내재적 동기 및 자기성찰 요인으로 구성한 후 각각의 요인들이 결과 변수로 어떠한 역할을 하는지 살펴보기 위해 문항꾸러미화를 통한 지표변수를 선정하였다. 최종 연구의 사용된 문항은 총 15 문항이다. 척도의 응답방식은 Likert식 5점 척도로 자기주도 학습능력에 따라 전혀 그렇지 않다(1점), 매우 그렇다(5점)로 구성되어 있으며, 평균점수가 높을수록 스스로 자기주도 학습 을 행하는 능력이 높다는 것을 의미한다. 문항 간 내적합치도 를 살펴보기 위하여 신뢰도를 분석한 결과 메타인지 .85, 정보 탐색 및 과제해결 .86 , 내재적 동기 및 자기성찰 .83으로 나타 났다.

\section{자료분석}

아동의 자기주도 학습능력에 대한 기본모형을 제시하고 모형 의 적합성을 마인드셋과 그릿을 통해 살펴보았다. 첫째, 아동 의 애착유형에 따라 각각의 변인들 간 차이가 나는지 살펴보 기 위해 SPSS 23.0 (IBM Co., Armonk, NY) F검증 및 Scheffé를 활용한 사후검증을 통하여 최종 애착유형을 분류하였다. 둘 째, 애착유형을 집단 간 분류한 기준을 토대로 주요 잠재변인 의 측정모형의 동일성을 검증하고 주요 변인 간의 차이가 존 재하는지 살펴보기 위해 AMOS (IBM Co., Armonk, NY)를 활 용한 잠재평균분석을 실시하였다. 셋째, 마인드셋과 그릿이 자기주도 학습능력과 어떠한 인과관계가 존재하는지 전체 집 단을 대상으로 구조방정식모델(SEM)을 활용해 검증한 후, 변 인간의 인과관계 패턴이 아동기 애착유형에 따라 유의한 차이 를 보이는지 다집단 분석을 활용해 검증해 보았다.

\section{Results}

\section{아동기 애착유형에 따른 구인 동일성 검증}

애착유형에 따라 마인드셋, 그릿, 자기주도 학습능력 변인 간 유형차이를 잠재평균분석을 활용하여 비교하기 전, 본 연구에 참여한 대상이 몇 가지 유형으로 분류되는지 $F$ 검증을 활용한 사후분석(Scheffé)을 통해 집단 간 동질성을 검증해 보았다. 분 석결과 회피 및 양가형이 동일집단으로 나타나 집단은 안정애 착집단과 불안정애착집단 두 가지로 분류되었다. 불안정애착 집단의 경우 회피 혹은 불안 차원에서 한 가지 이상의 부정적 
Table 2

Result of Invariance Verification

\begin{tabular}{lccccc}
\hline \multicolumn{1}{c}{ Model } & $\chi^{2}$ & $d f$ & TLI & CFI & RMSEA \\
\hline Model 1: Configural invariance & 179.52 & 78 & .975 & .985 & .041 \\
Model 2: Measurement invariance & 197.85 & 85 & .974 & .984 & .041 \\
Model 3: Measurement and scalar invariance & 360.90 & 97 & .948 & .962 & .059 \\
Model 4: Measurement, scale and invariance & 416.51 & 103 & .941 & .954 & .062 \\
\hline
\end{tabular}

Table 3

Analysis of Latent Mean Difference between Attachment Types

\begin{tabular}{lcccc}
\hline \multicolumn{1}{c}{ Variable } & Secure & Insecure & $p$ & Effect size $(d)$ \\
\hline Fixed mindset & 0 & $.539^{*}$ & .001 & .416 \\
Growth mindset & 0 & $-.892^{*}$ & .001 & .685 \\
Grit & 0 & $-.199^{*}$ & .001 & .152 \\
Meta cognition & 0 & $-.383^{*}$ & .001 & .660 \\
Intrinsic motivation & 0 & $-.366^{*}$ & .001 & .593 \\
Problem solving & 0 & $-.357^{*}$ & .001 & .608 \\
\hline
\end{tabular}

${ }^{*} p<.05$.

측면을 가지고 있다고 보고한 Bartholomew와 Horewiz (1991) 의 연구보고 결과에서처럼 애착유형은 두 가지 차원으로 분 류될 수 있음을 알 수 있다. 구조방정식에서 제시하는 적정 표 본의 크기를 Joreskog와 Sorbom (1989)은 관측변수가 12개 미 만인 경우 적절한 표본의 크기는 240 정도로 제시하고 있다. 본 연구에 참여한 아동들의 애착유형을 살펴보았을 때, 안정 형은 432 명, 회피형은 207명, 양가형은 158 명으로 나타났으므 로, 회피형과 양가형을 동일집단으로 보고 최종 안정애착(432 명)과 불안정애착(365명) 집단으로 분류하여 집단에 따른 검 증을 실시하였다. 집단 간 차이를 검증하는 방법으로 $F$ 검증이 주로 활용되지만 측정오차를 고려하지 않기 때문에 결과에서 왜곡될 가능성을 가진다. 따라서 측정오차를 고려한 잠재평균 분석을 활용하여 집단 간 차이검증을 살펴보고자 하였다. 잠 재평균분석을 위해서 형태동일성과 측정동일성, 절편동일성 이 성립되어야 하기 때문에(Hong, Malik, \& Lee, 2003). 자기주 도 학습능력, 그릿, 마인드셋 변인에 대하여 동일성 검증을 실 시하였다. 모형의 적합도 검증을 위해 RMSEA를 비롯한 TLI, $\mathrm{CFI}$ 값을 살펴볼 필요가 있는데, RMSEA는 .08 이하, TLI와 $\mathrm{CFI}$ 는 .90 이상이면 적합도가 좋다고 할 수 있다(Bentler, 1990; Browne \& Cudeck, 1993). 모형의 형태동일성 검증을 위해 자 기주도 학습능력, 마인드셋, 그릿 변인에 대한 측정모형을 아 동기 애착유형 집단에서 비교해 보았다(Table 2).

첫째, 모든 잠재변수 간 상관관계를 허용하고 모수의 측정
을 자유롭게 추정토록 한 모형 1 의 적합도는 만족할 수준으 로 나타났다. 둘째, 아동기 애착유형에 따라 적재치를 동일하 게 부여한 모형 2 는 모형 1 의 적합도와 거의 유사하였다. 형 태동일성 모형과 측정동일성 모형의 $\chi^{2}$ 값의 차이는 유의미하 기 때문에 $\left(\Delta \chi^{2}(7, N=797)=18.33, p<.025\right), \chi^{2}$ 값의 차이에 의 한 측정동일성은 기각되었다. 하지만, 모형의 간명성을 고려 하는 지수인 TLI와 CFI, RMSEA의 적합도는 형태동일성 모형 에 비해 나빠지지 않았으므로 동일성제약은 기각되지 않을 수 있다. 셋째, 모형 2 와 모형 3 의 적합도를 검증해보았다. 측정 동일성과 절편동일성 모형 간 적합도를 비교한 결과, $\chi^{2}$ 값에 서 유의미한 차이를 보였으나 $\left(\Delta \chi^{2}(12, N=797)=163.05, p<\right.$ .005), 절편동일성 모형에서의 적합도지수가 측정동일성 모형 에서의 적합도 지수에 비해 나빠지지 않았으므로 절편동일성 모형 또한 성립되었다. 형태 및 측정, 절편 동일성 검증단계에 서 적합도에서 차이를 보이지 않았는데, 이러한 결과는 애착 유형별 집단에서 측정도구와 절편이 동일하게 작동하고 있음 을 의미한다. 잠재평균분석을 위해 안정애착 집단의 잠재평균 을 0 으로 고정한 후, 다른 집단의 잠재평균값을 추정하여 참조 집단에 대한 상대적 값을 Table 3을 통해 살펴보았다.

잠재평균결과, 모든 요인에서 애착유형별 집단 간 차이가 존재하고 있음을 알 수 있다. 안정애착유형은 불안정애착유형 에 비해 성장마인드셋을 비롯한 그릿, 메타인지, 내재적 동기 및 자기성찰, 정보탐색 및 과제해결 능력이 높은 것으로 나타 
Table 4

Descriptive Statistics and Correlations for Variables

\begin{tabular}{|c|c|c|c|c|c|c|c|c|c|c|c|c|c|}
\hline \multicolumn{2}{|c|}{ Variable } & 1 & 2 & 3 & 4 & 5 & 6 & 7 & 8 & 9 & 10 & 11 & 12 \\
\hline & 2 & $.82^{*}$ & - & $-.17^{*}$ & $-.22^{*}$ & $-.35^{*}$ & $-.31^{*}$ & $-.51^{*}$ & $-.47^{*}$ & $-.45^{*}$ & $-.48^{*}$ & $-.46^{*}$ & $-.47^{*}$ \\
\hline Growth mindset & 4 & $-.39 *$ & $-.38^{*}$ & $.84^{*}$ & - & $.17^{*}$ & $.16^{*}$ & $.55^{*}$ & $.41^{*}$ & $.42^{*}$ & $.39^{*}$ & $.42^{*}$ & $.36^{*}$ \\
\hline Grit & 5 & $-.35^{*}$ & $-.37^{*}$ & $.40^{*}$ & $.37^{*}$ & - & $.64^{*}$ & $.53^{*}$ & $.52^{*}$ & $.49^{*}$ & $.49^{*}$ & $.52^{*}$ & $.53^{*}$ \\
\hline \multirow[t]{2}{*}{ Meta cognition } & 7 & $-.56^{*}$ & $-.55^{*}$ & $.62^{*}$ & $.62^{*}$ & $.46^{*}$ & $.44^{*}$ & - & $.70^{*}$ & $.70^{*}$ & $.69^{*}$ & $.71^{*}$ & $.69^{*}$ \\
\hline & 8 & $-.43^{*}$ & $-.44^{*}$ & $.56^{*}$ & $.55^{*}$ & $.44^{*}$ & $.36^{*}$ & $.73^{*}$ & - & $.69^{*}$ & $.67^{*}$ & $.70^{*}$ & $.74^{*}$ \\
\hline \multirow[t]{2}{*}{ Intrinsic motivation } & 9 & $-.42^{*}$ & $-.48^{*}$ & $.62^{*}$ & $.58^{*}$ & $.46^{*}$ & $.38^{*}$ & $.67^{*}$ & $.64^{*}$ & - & $.73^{*}$ & $.70^{*}$ & $.63^{*}$ \\
\hline & 10 & $-.41^{*}$ & $-.43^{*}$ & $.64^{*}$ & $.59^{*}$ & $.45^{*}$ & $.37^{*}$ & $.57^{*}$ & $.59^{*}$ & $.75^{*}$ & - & $.65^{*}$ & $.66^{*}$ \\
\hline$S D$ & & 1.24 & 1.19 & 1.27 & 1.26 & .91 & .98 & .92 & .96 & .94 & 1.01 & .88 & .94 \\
\hline Skewness & & -.22 & -.17 & -.39 & -.41 & -.12 & .23 & -.09 & -.17 & -.32 & -.21 & -.24 & -.14 \\
\hline Kurtosis & & -.95 & -.93 & -.91 & -.95 & .16 & -.03 & .04 & -.01 & .13 & -.33 & .37 & .07 \\
\hline
\end{tabular}

Note. Below the diagonal is the secure attachment group; Above the diagonal is the insecure attachment group.

${ }^{*} p<.05$.

났으며, 불안정애착유형은 안정애착유형에 비해 고정마인드 셋에 더 높은 것으로 나타났다. 또한, 잠재평균분석은 효과크 기를 통해 일반적 측정기준에 부합하는 값을 제시할 수 있는 데, Cohen (1988)이 제시한 기준에 따르면 $d$ 값이 .2보다 작으 면 작은 값, .5보다 작으면 중간 값, .8 이상이면 큰 값으로 해석 한다. 본 연구에서는 아동의 그릿은 효과크기가 작은 것으로 나타났으며, 나머지 요인들(마인드셋, 메타인지, 내재적 동기 및 자기성찰, 정보탐색 및 과제해결)에서는 효과크기가 중간 인 것으로 나타났다. 이러한 결과를 토대로 집단에 따른 변인 들 간 인과관계에서 차이를 살펴보았다.

\section{측정변인 간의 상호상관행렬 및 기술 통계치}

측정 변인 간 상관행렬, 각 측정변인들의 평균 및 표준편차를 추정한 결과는 Table 4 와 같다. 연구결과를 살펴보면 애착유형 에 관계없이 모든 변인에서 유의한 상관을 보이는 것으로 나 타났다. 구조방정식 모형을 해석하는데 있어서 각 변인들의 정상분포조건을 충족하여야 하기 때문에 각 변인들에 대한 왜도 및 첨도를 살펴보았는데, 왜도는 .41 이하, 첨도는 .95 이 하로 나타남에 따라 Hong 등(2003)이 제안한 기준을 충족하 는 것으로 나타났다. 이러한 결과를 토대로 애착유형별 변인
간 인과관계를 살펴보았다.

\section{애착유형에 따른 변인 간 영향력 차이검증}

아동기 애착유형에 따라 모든 변인에서 차이가 존재하고 있음 이 검증되었으므로, 각 변인 간 관계를 검증하는 경로모형을 활용하여 인과관계 및 유형 별 차이를 비교해 보았다. 먼저, 요 인 적재치에 동일성 제약을 한 모형의 적합도를 살펴본 결과, TLI를 비롯한 CFI, RMSEA 값에서 만족할 만한 적합도를 보 였다 $\left(\chi^{2}(90, N=797)=339.31, \mathrm{TLI}=.95, \mathrm{CFI}=.96, \mathrm{RMSEA}=\right.$ .06).

아동기 애착유형 별 집단에서의 경로계수는 Table 5와 Figure 1, Figure 2와 같다.

아동기 애착유형에 관계없이 마인드셋, 그릿, 자기주도 학 습능력 요인 간 인과관계에서 모두 유의한 영향력을 미치는 것으로 나타났다. 연구결과를 구체적으로 살펴보면 다음과 같 다. 첫째, 아동의 성장마인드셋과 그릿이 높아지면 그들의 자 기주도 학습능력(메타인지, 내재적 동기, 과제해결능력)은 높 아지지만 고정마인드셋이 높아지면 자기주도 학습능력(메타 인지, 내재적 동기, 과제해결능력)이 낮아지는 것으로 나타났 다. 둘째, 아동의 성장마인드셋이 높아지면 그들의 그릿이 높 
Table 5

Parameter Estimates by Attachment Type (Model with Invariance Constraints)

\begin{tabular}{lllll}
\hline & \multicolumn{2}{c}{ Parameter } & Secure & Insecure \\
\hline Fixed mindset & $\rightarrow$ & Meta cognition & $-.12(-.17)^{*}$ & $-.12(-.16)^{*}$ \\
Growth mindset & $\rightarrow$ & Meta cognition & $.34(.40)^{*}$ & $.29(.43)^{*}$ \\
Grit & $\rightarrow$ & Meta cognition & $.74(.53)^{*}$ & $.83(.73)^{*}$ \\
Fixed mindset & $\rightarrow$ & Intrinsic motivation & $-.07(-.10)^{*}$ & $-.13(-.16)^{*}$ \\
Growth mindset & $\rightarrow$ & Intrinsic motivation & $.42(.50)^{*}$ & $.24(.34)^{*}$ \\
Grit & $\rightarrow$ & Intrinsic motivation & $.60(.42)^{*}$ & $.81(.68)^{*}$ \\
Fixed mindset & $\rightarrow$ & Problem solving & $-.06(-.10)^{*}$ & $-.10(-.12)^{*}$ \\
Growth mindset & $\rightarrow$ & Problem solving & $.22(.30)^{*}$ & $.21(.29)^{*}$ \\
Grit & $\rightarrow$ & Problem solving & $.84(.68)^{*}$ & $.93(.78)^{*}$ \\
Fixed mindset & $\rightarrow$ & Grit & $-.21(-.41)^{*}$ & $-.33(-.49)^{*}$ \\
Growth mindset & $\rightarrow$ & Grit & $.20(.34)^{*}$ & $.08(.12)^{*}$ \\
\hline
\end{tabular}

Note. Numbers are non-standardized coefficients and standardized coefficients are given in parentheses.

${ }^{*} p<.05$.

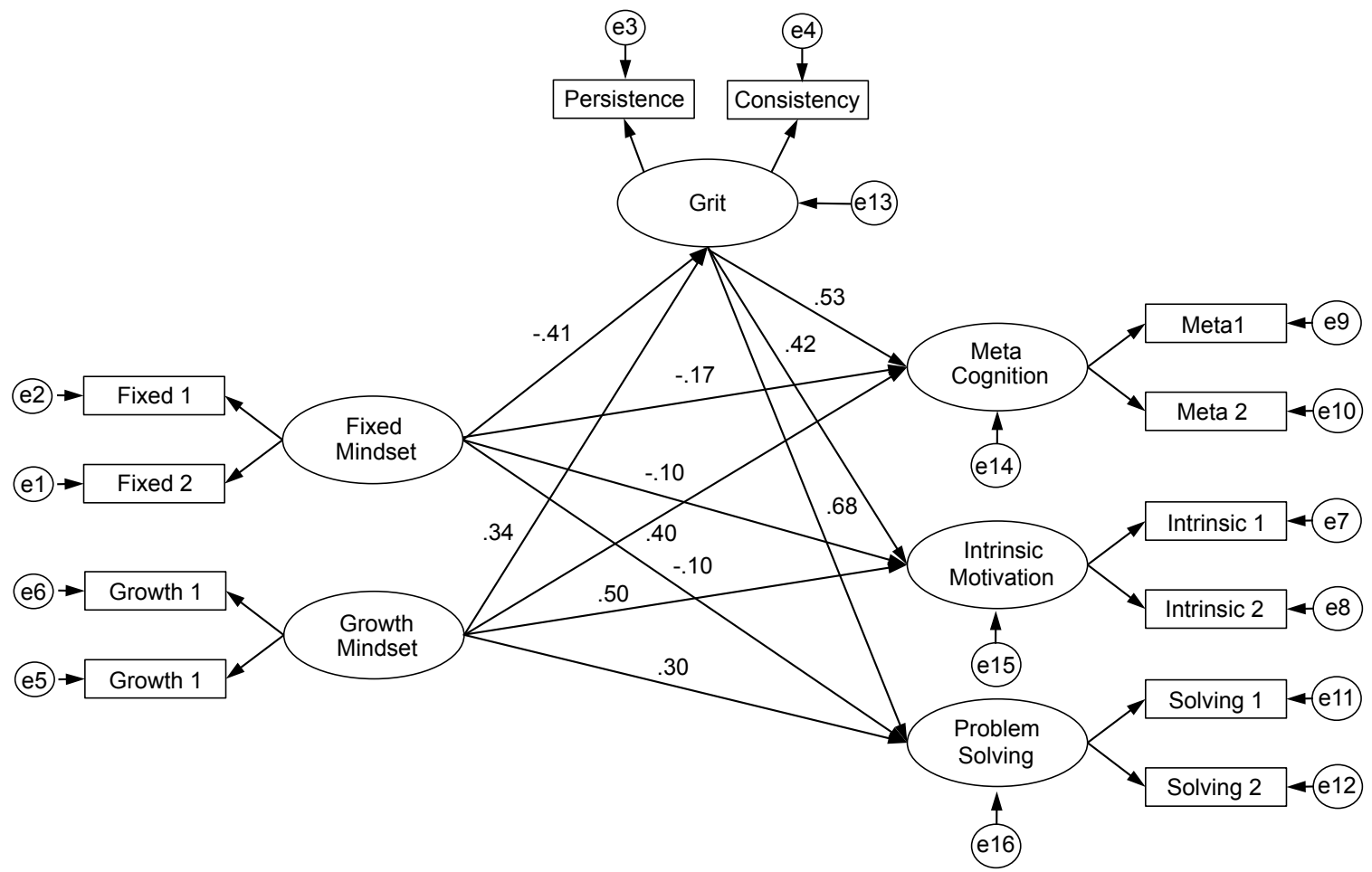

Figure 1. Result of secure attachment.

아지지만 고정마인드셋이 높아지면 그릿이 낮아지는 것으로 나타났다.

다음으로, 두 집단 사이에 존재할 수 있는 경로계수 간 유 의미한 차이를 살펴보기 위해 모형 내에 존재하는 11 개의 경 로계수에 동일화 제약을 가한 모형 11 개를 기저모형과 비교
하였다. Table 6에서 제시된 바와 같이 모든 경로계수까지 동 일화 제약을 가해도 모델의 적합도는 거의 변하지 않았다 $\left(\Delta \chi^{2}\right.$ $(11, N=797)=35.33, \Delta \mathrm{TLI}=-.01, \triangle \mathrm{RMSEA}=.01)$. 성장마인 드셋이 내재적 동기에 미치는 경로 $\left(\Delta \chi^{2}(1, N=797)=10.39, p\right.$ <.05)와 성장마인드셋이 그릿에 미치는 경로 $\left(\Delta \chi^{2}(1, N=797)\right.$ 


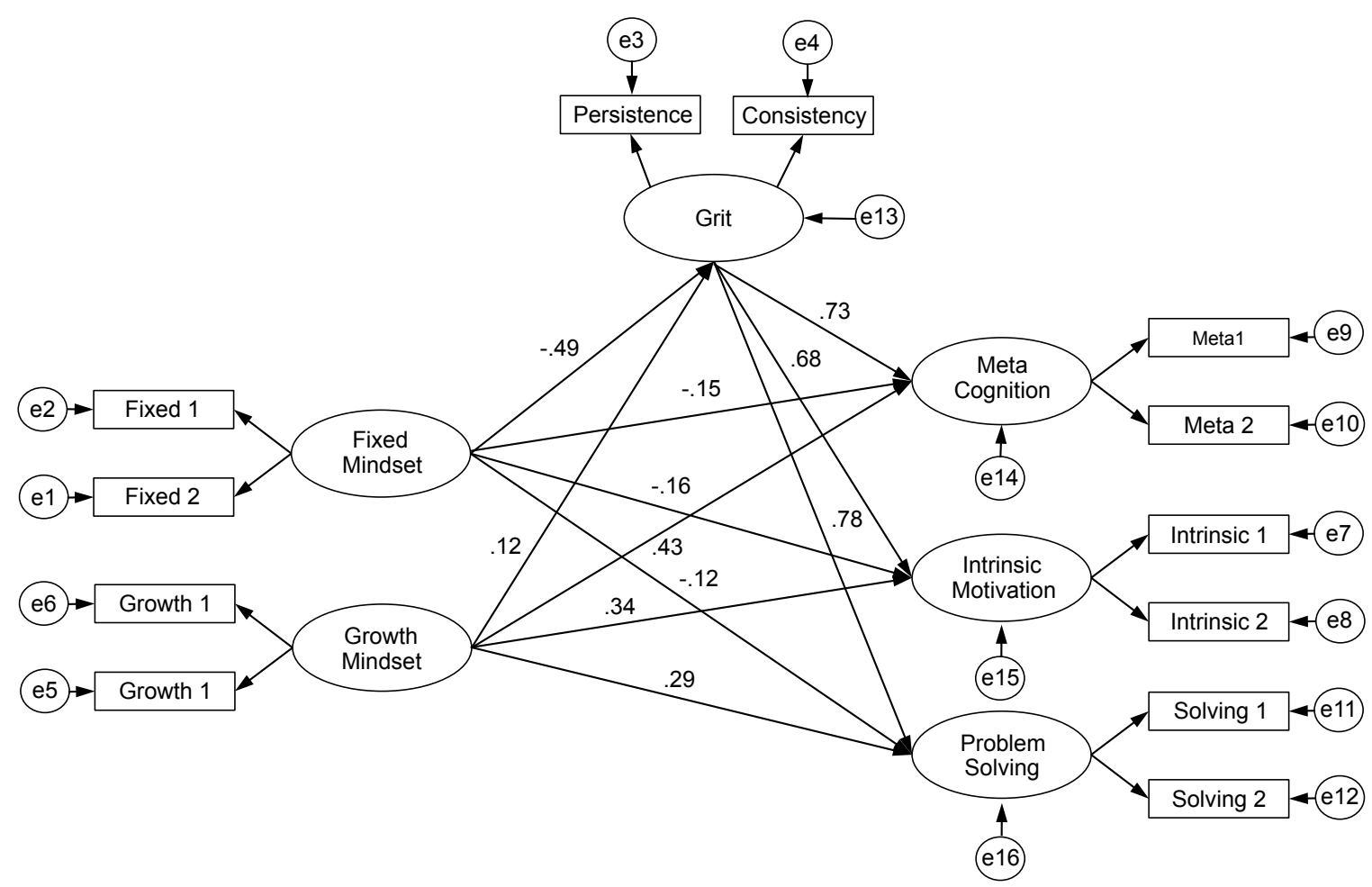

Figure 2. Result of insecure attachment.

\section{Table 6}

Comparison of Model with Invariance Constraints Difference Between Attachment Types

\begin{tabular}{|c|c|c|c|c|c|}
\hline \multicolumn{3}{|c|}{ Model with invariance constraints } & \multirow{2}{*}{$\frac{\Delta \text { Degree of freedom }}{1}$} & \multirow{2}{*}{$\frac{\Delta \chi^{2}}{.02}$} & \multirow{2}{*}{$\frac{\Delta \mathrm{TLI}}{-.01}$} \\
\hline Fixed mindset & $\rightarrow$ & Meta cognition & & & \\
\hline Growth mindset & $\rightarrow$ & Meta cognition & 1 & .74 & -.01 \\
\hline Fixed mindset & $\rightarrow$ & Intrinsic motivation & 1 & .86 & -.01 \\
\hline Growth mindset & $\rightarrow$ & Intrinsic motivation & 1 & $10.39^{*}$ & .01 \\
\hline Fixed mindset & $\rightarrow$ & Problem solving & 1 & .35 & -.01 \\
\hline Growth mindset & $\rightarrow$ & Problem solving & 1 & .08 & -.01 \\
\hline Grit & $\rightarrow$ & Problem solving & 1 & .38 & -.01 \\
\hline Fixed mindset & $\rightarrow$ & Grit & 1 & 3.12 & -.01 \\
\hline Growth mindset & $\rightarrow$ & Grit & 1 & $5.51^{*}$ & .00 \\
\hline
\end{tabular}

${ }^{*} p<.05$.

$=5.51, p<.05)$ 에 대한 동일화 제약에서 통계적으로 유의미한 차이가 나타났다.

유의미한 차이를 보이는 두 가지 경로(Table 6)들 중 두 집 단 모두에서 유의한 영향력을 가지며, 동일화 제약에서 통계 적으로 유의한 최종경로(Tabel 5)는 성장마인드셋이 내재적 동기와 그릿에 미치는 경로로 나타났다. 불안정 애착집단 $(\beta=$
$34, p<.05)$ 보다 안정애착 집단 $(\beta=.50, p<.05)$ 에서의 성장마 인드셋이 내재적 동기를 더욱 증가시키는 요인으로 작용하고 있으며, 불안정 애착집단 $(\beta=.12, p<.05)$ 보다 안정애착 집단 $(\beta$ $=.34, p<.05)$ 에서의 성장마인드셋이 그릿을 더욱 증가시키는 요인으로 작용함을 알 수 있다. 즉 아동의 성장마인드셋은 안 정애착이 선행되었을 때 강력한 원인으로 작용하여 자신들의 
내재적 동기와 그릿을 더욱 유의하게 증가시킬 수 있음을 의 미한다.

\section{Results}

본 연구에서는 아동의 자기주도 학습능력을 결과변수로 놓고, 이에 영향을 미치는 원인변수로 고정 및 성장 마인드셋, 그릿 을 선정하여 연구를 진행하였다. 연구결과를 중심으로 논의하 면 다음과 같다.

첫째, 아동기 애착유형에 따라 마인드셋, 그릿, 자기주도 학 습능력 간 평균차이를 검증한 결과, 모든 요인에서 유의한 차 이를 보이는 것으로 나타났다. 먼저, 애착유형에 따른 마인드 셋의 차이를 살펴본 결과는 다음과 같다. 불안정애착을 형성 한 아동의 경우 안정애착을 형성한 아동에 비해 고정마인드 셋이 높은 것으로 나타났으며, 성장마인드셋의 경우 안정애착 아동이 더 높은 점수를 보이는 것으로 나타났다. 이러한 결과 는 부모와 충분한 신뢰를 바탕으로 안정애착이 형성되면 자신 이 무언가를 해낼 수 있다고 확신하는 자신감을 가질 수 있다 고 보고한 Narvaez (2013)의 연구결과와 일치한다.

관계에서 어려움을 겪는 상황에서도 애정이 동반된 사회적 애착이 높을 경우 이를 극복하고 해결하려는 경향이 높다고 보고한 Carter (1998)의 연구결과는 아동이 고정 및 성장 마인 드셋을 형성하는데 있어서 애착안정성은 매우 중요한 요인으 로 작용할수 있음을 말해주고 있다. 부모와의 부적절한 애착 관계는 자녀의 도전에 대한 부정적 반응을 유발시키며 무기력 감을 유발시킨다는 Dweck (2007)의 연구결과는 고정마인드셋 을 향상시키는 원인으로 불안정애착이 중요한 요인으로 작용 할 수 있음을 말해주고 있다. 어린 시절 부모와의 부적절한 애 착관계는 자녀를 무능력하게 만들 수 있으므로(Bartholomew, 1990) 아동의 마인드셋 성장을 위한 기초작업으로 안정애착 형성이 먼저 이루어질 필요성을 말해주고 있다.

다음으로 아동기 애착유형에 따라 그릿의 차이를 살펴본 결과, 안정애착을 지닌 아동이 불안정애착을 지닌 아동보다 더 높은 수준의 그릿을 가지는 것으로 나타났다. 이러한 결과 는 부모와 안정애착을 형성할수록 자녀의 흥미의 지속성, 꾸 준함, 열정 등이 높아질 수 있다고 보고한 Duckworth (2016)의 연구와 일치한다. 안전기지에 대한 확신을 가진 자녀는 탐색 활동이 높아질 수 있으며(Holmes, 2014), 부모와 분리-개별화 가 잘 이루어지기 때문에 독립적인 활동이 가능하게 된다(H. S. Jang, 2002). 부모와의 관계에서 불안정애착을 형성한 자녀
는 그릿이 낮아질 수 있다고 보고한 Mandelbaum (2016)의 연 구 또한 안정애착 형성의 중요성을 이야기하고 있다. 실제, 그 릿 관련 선행연구들을 살펴보았을 때 표면적으로 지각된 양육 태도를 중심으로 연구들이 많이 진행되고 있지만 이를 내면화 한 애착이 더 높은 영향력을 가진다고 보고되고 있다(Levy \& Steele, 2011). 이처럼, 그릿 관련 기초연구로써 애착은 매우 중 요한 요소임을 선행연구 및 본 연구의 결과를 통해 확인할 수 있었다.

끝으로 아동기 애착유형에 따라 자기주도 학습능력의 차 이를 살펴본 결과, 아동기 안정애착이 형성될 경우 그들의 메 타인지, 내재적 동기, 정보탐색 및 과제해결 능력이 높아질 수 있는 것으로 나타났다. 교사와의 안정애착은 학생의 내재적 동기를 높이는 주요요인으로 작용할 수 있다고 보고한 M.-J. Jang (2018)의 연구결과와 안정애착이 형성될 경우 메타인지 가 높아질 수 있다는 Fonapy (1997)의 연구결과는 본 연구의 결과와 맥을 같이 한다. Egeci와 Gencoz (2011)는 애착유형에 따라 과제해결능력 및 상호작용에서 기술의 차이를 보이는지 살펴본 결과, 안정애착이 동반될 경우 문제에 직면하였을 때 이를 해결하기 위한 행동차원의 접근이 불안정애착을 가진 사 람보다 높은 것으로 나타났다. 이처럼, 애착유형은 아동의 메 타인지를 비롯한 내재적 동기, 과제해결 능력을 높이는 주요 요인임을 알 수 있으며, 본 연구의 결과 또한 이러한 선행연구 를 뒷받침 하고 있음을 발견할 수 있다. 따라서 자기주도 학습 능력을 높이기 위한 연구 과정에서 애착유형 별 파악이 선행 되어야 한다.

둘째, 아동기 애착유형에 따른 인과관계의 차이를 살펴본 결과, 성장마인드셋에서 그릿에 이르는 경로와 성장마인드셋 에서 내재적 동기에 이르는 경로에서 유의한 차이가 존재하고 있음을 알 수 있었다. 먼저, 각각의 애착유형에 따른 인과관계 의 유의성을 살펴보았다. 그 결과, 애착유형에 관계없이 두 집 단 모두에서 마인드셋과 그릿은 자기주도 학습능력을 예측하 는 요인으로 나타났다. 아동기 성장마인드셋이 높을수록 내재 적 동기와 메타인지, 정보탐색 및 과제해결 능력이 높아지는 반면, 고정마인드셋이 높을수록 그들의 내재적 동기와 메타인 지, 정보탐색 및 과제해결 능력이 낮아지는 것으로 나타났다. 성장마인드셋이 높은 사람은 자신의 노력을 통해 학습능력을 향상시킬 수 있다는 인지적 사고와 더불어 능력을 향상시키기 위한 목표설정을 하며, 이를 실행하는 능력이 매우 높을 수 있 다고 보고한 Claro 등(2016)의 연구결과는 본 연구를 지지하고 있다. 이에 반해, 고정마인드셋이 높은 사람은 자신의 지능과 학습능력은 이미 타고난 자질로 생각하기 때문에 고정되어 있 
다고 생각하기 때문에 노력해도 바꿀 수 없다는 부정적 사고 를 하며, 변화시키고자 하는 목적의식이 낮으며 무언가를 해 결하기 위한 추가적인 노력이나 끈기를 보이지 않는 특징을 보일 수 있다는 Dweck (2007)의 연구 또한 본 연구와 맥을 같 이 한다. 이처럼 자기주도 학습능력을 증가 혹은 감소시키는 원인으로 아동이 가지는 마인드셋이 매우 중요한 역할을 한다 는 측면은 아동의 마인드셋 변화를 위한 관련 프로그램 및 연 구가 이루어질 필요성을 알 수 있다.

그릿이 높을수록 내재적 동기와 메타인지, 과제해결능력 이 높아질 수 있는 것으로 나타났다. 이러한 결과는 그릿이 높 은 사람은 목적달성을 위해 끈임없이 노력하는 행동적 차원의 실행능력이 매우 높을 수 있다는 Duckworth 등(2007)의 연구 결과는 정보탐색 및 과제해결 능력을 높이는 요인으로 그릿이 작용한다는 본 연구의 결과와 맥을 같이한다. 또한, 그릿이 높 을 경우 목표지향성을 비롯한 긍정적으로 해낼 수 있다는 인 지적 특성을 보인다는 측면(Guglielmino \& Guglielmino, 2006; Hiemstra, 1994)은 자기주도 학습능력 예측요인으로 그릿이 매우 중요한 역할을 한다는 본 연구와 일치한다. 이러한 결과 를 토대로 그릿을 높이기 위한 차원적 접근의 필요성을 본 연 구를 통해 발견할 수 있다.

성장마인드셋이 높을수록 그릿이 높아지는 반면, 고정마인 드셋이 높을수록 그들의 그릿은 낮아지는 것으로 나타났다. 고정마인드셋이 높은 사람은 역경을 겪는 순간 비관적인 해석 을 하여 도전상황을 피하거나 행동실행으로 옮기려 하지 않는 반면, 성장마인드셋이 높은 사람은 그것을 이겨낼 수 있을 것 이라는 낙관적 해석을 하기 때문에 그것을 극복하려는 끈기 있는 모습을 보일 수 있다고 보고한 Duckworth (2016)의 연구 결과는 본 연구와 맥을 같이 하고 있다. 청소년의 뇌 발달 과정 을 추적 조사한 Ramsden 등(2011)의 연구에서 자신의 지능이 변화할 수 있다는 사고를 가진 청소년들은 지속적인 노력과정 을 통하여 자신의 지능을 향상시켰다고 보고하고 있다. 이처 럼, 개인이 가지는 끈기는 그들의 마인드셋에 따라 강화될 수 있으므로 성장마인드셋을 강화시키기 위한 방안적 연구가 무 엇보다 필요하다.

다음으로, 아동기 애착유형에 따라 인과관계에서 유의미 한 차이를 보이는지 살펴본 결과, 성장마인드셋과 그릿, 성장 마인드셋과 내재적 동기에 이르는 경로에서 유의한 차이를 보이고 있었다. 이는 안정애착은 아동의 성장마인드셋은 그 들의 그릿과 내재적 동기를 더욱 높이는 중요한 요인으로 작 용할 수 있음을 의미한다. 부모와의 안정적 애착관계를 형성 한 자녀는 개인의 노력을 통해 자신의 능력이 변화될 수 있다
고 믿는 성장가능성이 불안정 애착관계를 형성한 자녀보다 높 기 때문에 그들의 무언가를 이루기 위한 동기 또한 높을 수 있 으며(Ma \& Chan, 2014), 부모와의 긍정적 상호작용을 통한 신뢰 관계 형성은 변화를 위해 끊임 없이 노력하는 지속성 또 한 향상시키는 요인으로 작용할 수 있는 것이다(Levy \& Steele, 2011). 즉, 부모와의 안정애착 형성이 선행될 경우 자신의 능 력을 향상시킬 수 있다는 믿음이 더욱 높아지게 됨으로써 그 들의 끈기와 목표를 향한 내재적 동기 또한 더욱 높아질 수 있 다는 점에서 아동기 안정애착의 중요성을 발견할 수 있다.

본 연구의 결과를 통해 나타난 의의는 다음과 같다. 첫째, 아동의 마인드셋과 그릿, 자기주도 학습능력을 높이기 위한 방안으로 아동기 애착이 매우 중요한 요소임을 발견할 수 있 었다. 아동의 행동을 예측하는 요인으로 외현화된 부모의 양 육방식이 주목받고 있지만, 양육태도를 이루는 내면화된 요소 인 안정애착 형성이 선행될 필요가 있다는 Levy와 Steele (2011) 의 연구결과 또한 안정애착 형성을 돕기 위한 차원적 접근의 필요성을 지지하고 있다. 나아가, 변인 간 인과관계 검증에서 도 아동기 애착유형에 따라 유의한 차이를 보이고 있음을 알 수 있다. 따라서, 아동기 애착유형 분류를 통한 접근을 토대로 한 관련 변인 간 인과관계 검증이 이루어질 필요가 있음을 본 연구를 통해 발견할 수 있었다는 점은 매우 큰 의의를 가진다. 둘째, 애착유형에 관계없이 아동이 가지는 고정마인드셋은 그 들의 그릿과 자기주도 학습능력을 낮추는 주요요인으로 작용 할 수 있음을 발견할 수 있었다. 즉, 고정마인드셋을 가질 경우 아동의 올바른 성장을 저해하는 주요요인으로 작용할 수 있다 는 측면에서 이를 해결하기 위한 접근적 방안이 모색될 필요 성을 본 연구를 통해 발견할 수 있다. 셋째, 아동이 가지는 성 장마인드셋은 그들의 끈기와 메타인지, 내재적 동기, 과제해 결 능력을 높이는 주요 요인임을 본 연구를 통해 발견할 수 있 다. 따라서, 아동의 성장마인드셋을 높이기 위한 제도적 차원 의 접근이 필요함을 본 연구를 통해 발견하였다는 점은 매우 큰 의의를 지닌다.

본 연구가 지닌 한계점과 추후 연구를 위한 제언은 다음과 같다. 본 연구에 참여한 아동은 일부 지역을 포함하고 있기 때 문에 일반화에 한계를 가진다. 따라서, 추후 연구에서는 다양 한 지역의 아동을 대상으로 표집하여 연구가 진행 된다면 연 구결과를 일반화 할 수 있을 것이다. 둘째, 본 연구에 참여한 대상자들의 인구사회학적 특성을 애착유형 별 분류 없이 빈도 를 제시하였다. 따라서, 추후 연구에서는 초등학생이 가지는 애착유형 빈도를 함께 제시한다면 청소년기, 성인기 애착유형 과 비교하여 연령증가에 따른 애착유형 변화추이를 예측할 수 
있을 것이다. 나아가, 종단 연구를 통한 애착유형 변화에 따른 인과관계 검증에서의 차이 값 변화를 함께 연구한다면 더욱 의미 있는 자료로 활용될 수 있을 것이다.

\section{Acknowledgements}

This study was supported by the 2019 research grant of Korean Association of Child Studies.

\section{Notes}

This article was presented at the 2020 Korean Association of Child Studies Spring Online Conference.

\section{Conflict of Interest}

No potential conflict of interest relevant to this article was reported.

\section{References}

\section{In English}

Bartholomew, K. (1990). Avoidance of intimacy: An attachment perspective. Journal of Social and Personal Relationships, 7(2), 147-178. doi:10.1177/0265407590072001

Bartholomew, K., \& Horowiz, L. M. (1991). Attachment styles among young adults: A test of a four-category model. Journal of Personality and Social Psychology, 61(2), 226-224. doi:10.1037/0022-3514.61.2.226

Bentler, P. M. (1990). Comparative fit indexes in structural models. Psychological Bulletin, 107(2), 238-246. doi:10.1037/00332909.107.2.238

Blackwell, L. S., Trzesniewski, K. H., \& Dweck, C. S. (2007). Implicit theories of intelligence predict achievement across an adolescent transition: A longitudinal study and an intervention. Child Development, 78(1), 246-263. doi:10.1111/j.14678624.2007.00995.x

Browne, M. W., \& Cudeck, R. (1993). Alternative ways of assessing model fit. In K. A. Bollen \& J. S. Long (Eds.), Testing structural equation models (pp. 136-162). Newbury Park, CA: Sage.
Carter, C. S. (1998). Neuroendocrine perspectives on social attachment and love. Psychoneuroendocrinology, 23(8), 779818. doi:10.1016/S0306-4530(98)00055-9

Claro, S., Paunesku, D., \& Dweck, C. S. (2016). Growth mindset tempers the effects of poverty on academic achievement. Proceedings of the National Academy of Sciences, 113(31), 8664-8668. doi:10.1073/pnas.1608207113

Cohen, J. (1988). Statistical power analysis for the behavioral sciences (2nd ed.). Mahwah, NJ: Lawrence Erbaum Associates.

Coppola, G., Vaughn, B. E., Cassiba, R., \& Costantini, A. (2006) The attachment script representation procedure in an Italian simple: Associations with adult attachment interview scales and with maternal sensitivity. Attachment \& Human Development, 8(3), 209-219. doi:10.1080/14616730600856065

Corno, L., \& Mandinach, E. B. (1983). The role of cognitive engagement in classroom learning and motivation. Educational Psychologist, 18(2), 88-108. doi:10.1080/00461528309529266

Duckworth, A. (2016). Grit: The power of passion and perseverance. New York: Scribner.

Duckworth, A., \& Gross, J. J. (2014). Self-control and grit: Related but separable determinants of success. Current Directions in Psychological Science, 23(5), 319-325. doi:10.1177/ 0963721414541462

Duckworth, A. L., Peterson, C., Matthews, M. D., \& Kelly, D. R. (2007). Grit: Perseverance and passion for long-term goals. Journal of Personality and Social Psychology, 92(6), $1087-$ 1101. doi:10.1037/0022-3514.92.6.1087

Duckworth, A. L., \& Quinn, P. D. (2009). Development and validation of the Short Grit Scale (Grit-S). Journal of Personality Assessment, 91(2), 166-174. doi:10.1080/00223890802634290

Duckworth, A. L., Quinn, P. D., \& Seligman, M. E. (2009). Positive predictors of teacher effectiveness. The Journal of Positive Psychology, 4(6), 540-547. doi:10.1080/17439760903157232

Dweck. C. S. (2007). Mindset: The new psychology of success. New York: Ballantine Books.

Dweck, C. S., Chiu, C. Y., \& Hong, Y. Y. (1995). Implicit theories and their role in judgments and reactions: A word from two perspectives. Psychological Inquiry, 6(4), 267-285. doi:10.1207/s15327965pli0604_1

Dweck, C. S., \& Leggett, E. L. (1988). A social-cognitive approach to motivation and personality. Psychological Review, 95(2), 256-273. doi:10.1037/0033-295X.95.2.256

Egeci, I. S., \& Gencoz, T. (2011). The effects of attachment styles, problem-solving skills, and communication skills on relationship satisfaction. Procedia-Social and Behavioral Sciences, 30, 2324-2329. doi: 10.1016/j.sbspro.2011.10.453

Eskreis-Winkler, L., Gross, J. J., \& Duckworth, A. L. (2016). Grit: Sustained self-regulation in the service of superordinate goals. In K. D. Vohs \& R. F, Baumeister (Eds.), Handbook of self-regulation: Research, theory and applications (3rd, pp. 
380-395). New York: Guilford.

Fernald, A., \& Kuhl, P. (1987). Acoustic determinants of infant preference for motherese speech. Infant Behavior and Development, 10(3), 279-293. doi:10.1016/0163-6383(87)90017-8

Fitzgerald, C. J., \& Laurian-Fitzgerald, S. (2016). Helping students enhance their grit and growth mindsets. Journal Plus Education, 14(3), 52-67.

Fonagy, P. (1997). Multiple voices vs. meta-cognition: An attachment theory perspective. Journal of Psychotherapy Integration, 7(3), 181-194. doi:10.1037/h0101122

Galen, L. (2011). The fundamentalist mindset: Psychological perspectives on religion, violence, and history. The International Journal for the Psychology of Religion, 21(3), 237-241. doi:10.1 080/10508619.2011.581583

Guglielmino, P. J., \& Guglielmino, L. M. (2006). Culture, selfdirected learning readiness, and per capita income in five countries. S.A.M. Advanced Management Journal, 71(2), 21-28.

Hazan, C., \& Shaver, P. (1987). Romantic love conceptualized as an attachment process. Journal of Personality and Social Psychology, 52(3), 511-524. doi:10.1037/0022-3514.52.3. 511

Hiemstra, R. (1994). Self-directed learning. In W. J. Rothwell \& K. J. Sensenig (Eds.), The sourcebook for self-directed learning (pp. 9-20), Amherst, MA: HRD Press.

Holmes, J. (2014). John Bowlby and attachment theory (2nd, ed.). London, England: Routledge.

Hong, S., Malik, M. I., \& Lee, M.-K. (2003). Testing configural, metric, scalar, and latent mean invariance across genders in sociology and autonomy using non-western sample. Educational and Psychology Measurement, 63(4), 636-654. doi:10.1177/0013164403251332

Joreskog, K. G., \& Sorbom, D. (1989). LISREL 7: A guide to the program and applications (2nd ed.). Chicago, IL: SPSS Inc.

Levy, J. M., \& Steele, H. (2011). Attachment and grit: Exploring possible contributions of attachment styles (from past and present life) to the adult personality construct of grit. Journal of Social and Psychological Sciences, 4(2), 16-49.

Ma, W. W., \& Chan, A. (2014). Knowledge sharing and social media: Altruism, perceived online attachment motivation, and perceived online relationship commitment. Computers in Human Behavior, 39, 51-58. doi:10.1016/j.chb.2014.06.015

Mandelbaum, T. (2016). The relationship between attachment and grit (Doctoral dissertation). Retrieved from https:// repository.brynmawr.edu/dissertations/138/

Molden, D. C., \& Dweck, C. S. (2006). Finding "meaning" in psychology: A lay theories approach to self-regulation, social perception, and social development. American Psychologist, 61(3), 192-203. doi:10.1037/0003-066X.61.3.192

Muris, P., Mayer, B., \& Meesters, C. (2000). Self-reported attachment style, anxiety, and depression in children. Social
Behavior and Personality: An International Journal, 28(2), 157-162. doi:10.2224/sbp.2000.28.2.157

Myers, C. A., Wang, C., Black, J. M., Bugescu, N., \& Hoeft, F. (2016). The matter of motivation: Striatal restingstate connectivity is dissociable between grit and growth mindset. Social Cognitive and Affective Neuroscience, 11(10), 1521-1527. doi:10.1093/scan/nsw065

Narvaez, D. (2013). Neurobiology and moral mindset. In K. Heinrichs, F. K. Oser, \& T. Lovat (Eds.), Handbook of moral motivation: Theories, models, applications (Vol. 7, pp. 323-340). Rotterdam, NL: Sense Publishers..

Pintrich, P. R., Marx, R. W., \& Boyle, R. A. (1993). Beyond cold conceptual change: The role of motivational beliefs and classroom contextual factors in the process of conceptual change. Review of Educational Research, 63(2), 167-199. doi:10.3102/00346543063002167

Ramsden, S., Richardson, F. M., Josse, G., Thomas, M. S. C., Ellis, C., Shakeshaft, C.,...Price, C. J. (2011). Verbal and nonverbal intelligence changes in the teenage brain. Nature, 479(7371), 113-116.

Skogland, M. A. C. (2017). The mindset of activity-based working. Journal of Facilities Management, 15(1), 62-75.

West, M. R., Kraft, M. A., Finn, A. S., Martin, R. E., Duckworth, A. L., Gabrieli, C. F., \& Gabrieli, J. D. (2016). Promise and paradox: Measuring students' non-cognitive skills and the impact of schooling. Educational Evaluation and Policy Analysis, 38(1), 148-170. doi:10.3102/0162373715597298

Zimmerman, B. J. (1989). A social cognitive view of self-regulated academic learning. Journal of Educational Psychology, 81(3), 329-339. doi:10.1037/0022-0663.81.3.329

Zimmerman, B. J. (2008). Investigating self-regulation and motivation: Historical background, methodological developments, and future prospects. American Educational Research Journal, 45(1), 166-183. doi:10.3102/0002831207312909

\section{In Korean}

Han, H. (2010). The effects of thematic integrated learning on the academic achievements and the self-directed learning ability of the sixth-graders in elementary school (Master's thesis). Retrieved from http://www.riss.kr/link?id=T11984150

Jang, H. S. (2002). Attachments to parents, separation-individuation and psychological adjustment in late adolescence. The Korean Journal of Development Psychology, 15(1), 101-121.

Jang, M.-J. (2018). The effect of middle school student's teacher attachment on their self-adjustive efficacy: The mediating effect of amotivation and intrinsic (Master's thesis). Retrieved from http://www.riss.kr/link?id=T14745721

Jeon, H. S. (2018). The relationship among university students' growth mindset, grit, intrinsic future-oriented goals and academic 
adjustment (Master's thesis). Retrieved from http://www. riss.kr/link?id=T14909190

Kim, H.-M., \& Hwang, M.-H. (2015). Validation of the Korean Grit Scale for children. The Journal of Education, 35(3), 6374. doi:10.25.020./je.2015.35.3.63

Kim, J. (2012). The effect of the elementary school children's adult attachment types on emotioanal regulation and self-efficacy (Master's thesis). Retrieved from http://www.riss.kr/ link?id=T12869147

Kwon, D.-H. (2018). Relationship among growth gindset, future time perspective, grit and procrastination. Asian Journal of Education, 19(3), 725-744. doi:10.15753/ aje.2018.09.19.3.725

Lee, J. Y., \& Baek, J. B. (2009). The mediating effects of the selfcontrol ability in the relationship of mother attachments and school life adjustment of elementary school students. The Journal of Korean Educational Forum, 8(1), 57-78.

Lee, S. (2016). A study on relationship between growth mindset, fixed mindset and grit of young adults: The mediating effects of resilience (Master's thesis). Retrieved from http://www.riss. $\mathrm{kr} /$ link?id=T14138967

Park, J. (2017). The effects of attributional feedback on academic achievement according to mindset, grit and self-control (Master's thesis). Retrieved from http://www.riss.kr/link?id=
T14508471

Park, Y. H. (2003). A study on validation of self-directed learning ability diagnostic scale for elementary higher graders (Doctoral dissertation). Retrieved from http://www.riss.kr/ link?id=T10375918

Yang, M.-H. (2002). The study on the relationship between selfregulated learning and academic achievement. Asian Journal of Education, 3(2), 47-70.

Yoo, N.-H., \& Lee, K.-H. (2005). The effects of attachment, psychological independence and emotional intelligence on career decision-making self-efficacy. Korean Journal of Counseling And Psychotherapy, 17(2), 451-466.

\section{ORCID}

Min Kyu Cho https://orcid.org/0000-0002-2170-8062

Received June 30, 2020

Revision received July 24, 2020

Accepted August 11, 2020 